\title{
Review of recent research in nano cellulose preparation and application from jute fibers
}

\author{
Ling Duan ${ }^{1,2, a}$, Weidong $Y u^{1,2, b}$ \\ ${ }^{1}$ College of Textiles, Donghua University, Shanghai 201620, China \\ ${ }^{2}$ Textile materials and Technologh Laboratory, Donghua University, Shanghai 201620, China

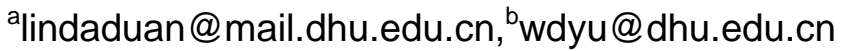

Keywords: Jute, Microfibrillated Cellulose (MFC), Nano cellulose whiskers (NCW), Nanocomposite

\begin{abstract}
Jute is the second most important fiber in the world, which is easy to grow on all types of soil from clay to sandy loam. The popularity of jute is attributable to its abundant and cheapness, and jute fiber is mainly used in the manufacture of coarse fabrics like bags, hessian, sacking, canvas and twines. Jute is rich in cellulose, which could be served as promising candidates for nano materials production. Nano cellulose features concerned its high strength and stiffness, renewability, low density, biodegradability, low thermal expansion coefficient and high aspect ratio. Fields of use of nanocellulose include reinforcement of nanocomposite materials, thickening agents, tissue engineering scaffolds, dry-strength additive for paper, filtration media, adsorbents, etc. This review summarizes progress in nanocellulose preparation and also discusses recent developments in nanocomposite fabrication based on jute fibers.
\end{abstract}

\section{Introduction}

Jute is the cheapest and the second most common natural fiber, which is used extensively in the manufacture of different types of packaging material for various agricultural and industrial products. Jute fiber is extracted from the inner bast tissues of the bark of the plant's stem[1]. Corchorus. Capsularis L.(White) and Corchorus.olitorius L.(Tossa), mostly cultivated for fibers, belong to the genus Corchorus, family Tiliaceae. The genus includes about 40 species. Jute is grown extensively in Bangladesh, India and China[2].

Development of nanomaterial's based on nanocellulosic substances is a rather new but rapidly developing research area. The nanocellulose exhibit excellent properties like high strength, high stiffness, high aspect ratio, low cost, renewability and biodegradability[3]. Many plants could be used as resources for nanocellulose extraction such as jute[4], sisal[5], rice husk[6]. The nanocellulose is suggested a wide range of potential commercial uses such as biomedicine[7], tissue engineering scaffolds[8]. The use of jute fibers in the nanomaterials area can bring prosperity and economic benefit of the traditional fiber, particularly from an environmental point of view. The aim of this review is to describe current state to the preparation and application of nanocellulosic materials from jute fibers.

\section{Structure of Jute fibers}

Jute fibers composed mainly of cellulose (59-71\%), hemicellulose (12-13\%), lignin $(11.8-12.9 \%)$, pectin $(0.2-4.4 \%)$ and wax/fat $(0.5 \%)[9]$. The lignin content of jute was high compared to other bast fibers. Therefore, it is difficulty to extract the cellulose with high purity. Cellulose is composed of $\beta$-d- glucopyranose units joined by $(1 \rightarrow 4)$ glycosidic links[10]. The hemicellulose of jute fiber is thought to consist mostly of polyuronides hexosans and xylan, Lignins are amorphous polymers consisting of phenylpropane units[11]. The reactivity of hydroxyl groups $(-\mathrm{OH})$ of cellulose at the C-2, C-3 and C-6 positions influenced the physical and chemical properties of the cellulose chain[12]. The interaction between the cellulose chains is tight due to the weaker Van der waals force and stronger intermolecular and intramolecular H-bonding[13]. It is extremely difficult to extract nanocellulose with relatively uniform particle size.

Morphologically, Jute fiber shows the multicellular appearance with hierarchical structure, which can be described as the concentric layers surrounding the lumen, and the surfaces covered 
with the gummy matter[14]. Jute fibers is composed of a number of ultimate cells with lignin and hemicellulose acting as cementing agents to give strength and flexibility to the fiber[15]. Several studies suggest that most of the hemicelluloses are present in the inter-fibrillar matrix within the ultimate cells, and most of the lignin is believed to be located in the in the middle lamella between the ultimate cells[16]. The outermost layer is the primary wall (P), followed by the secondary wall (outer layer S1, middle layer S2, inner layer S3). Jute cell wall organization as shown in Fig. 1. In the primary layer, the elementary fibrils have in general a crisscross arrangement. And the secondary layer straight fibrils are observed in the axial section. Some helically oriented fibrils are present in the upper portion of the secondary layer[17].

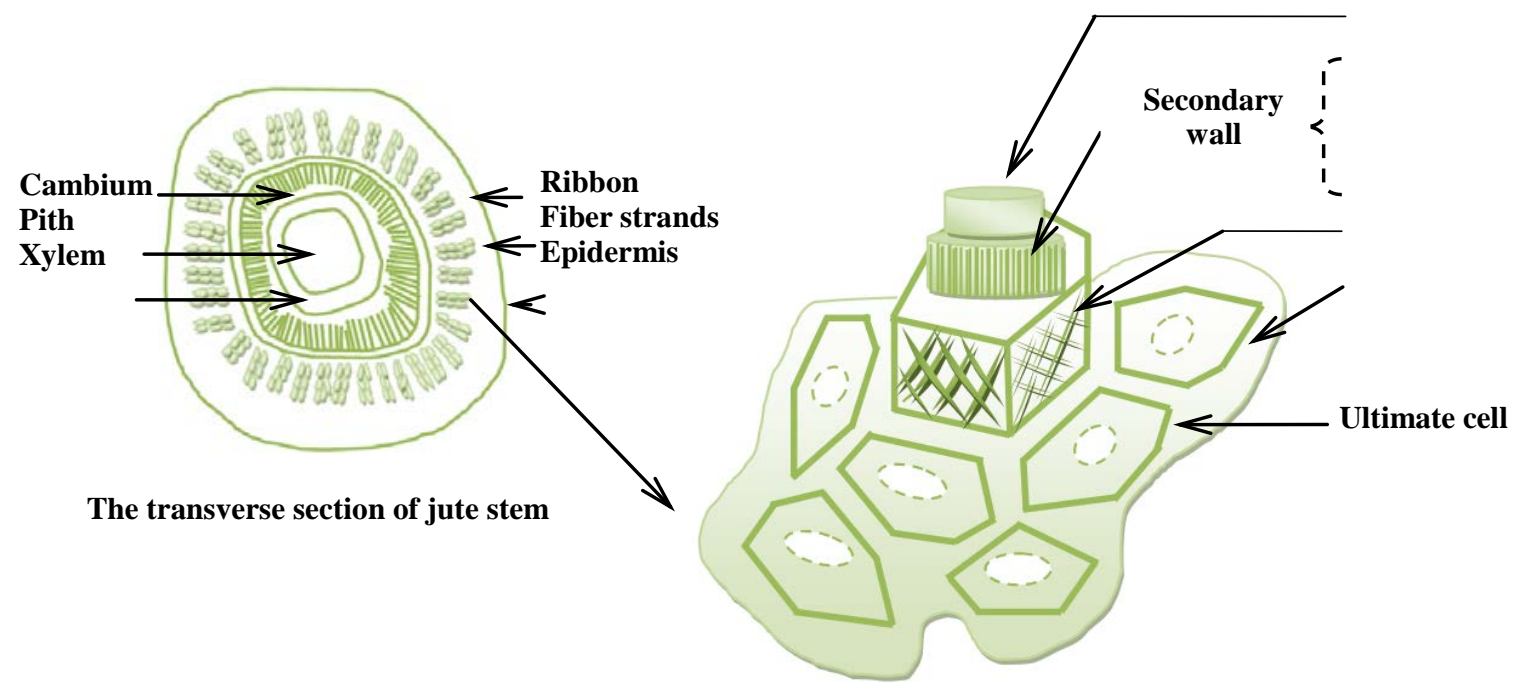

The cross section of jute bundle fibers

Fig.1 Scheme of the jute cell wall organization[2,9,17]

Cellulose molecules are linked together to form elementary fibrils, which have a diameter of around 2 20 nm depending on their origin. The elementary fibril is made up of amorphous and crystalline parts[18]. The crystalline areas are mainly connects with the rigidity, density and swelling properties in the fiber structure; whereas the less ordered amorphous areas are mainly refers to the fiber softness, flexibility, and extensibility[19]. Some researchers investigated of jute microstructure. The lateral width of the microfibrils has been measured as $28.0 \pm 3.0 \AA$ by Heyn with negative staining of sections methods [20]. Mukherjee extracted elongated particles from jute by sulphuric acid. The mean width and thickness of the particles are about $85 \AA$ and $20 \AA$ respectively[21].

\section{Jute nanocellulose}

Two kinds of nanoparticles could be extracted from jute: Microfibrillated Cellulose (MFC) with web like structure and nano cellulose whiskers (NCW) with elongated crystalline rod-like appearance. The NCW is used to designate nanoparticles with a relatively low aspect ratio, whereas the MFC is referred as cellulose microfibrils with lateral dimensions around 10 to $100 \mathrm{~nm}$. The webs like structure and micrometer length scale are the distinct characters of MFC[22].

\subsection{Microfibrillated Cellulose (MFC)}

Microfibrillated Cellulose (MFC) is obtained through a mechanical treatment such as high pressure homogenizing, grinding, microfluidizer , ultrasonication, ball milling, cryocrushing and steam explosion. Purification by the chemical pretreatment usually was carried out before nanofibrillation for lignocellulosic fibers. This process results in the solubilisation of lignin, pectins and hemicelluloses.

Microfibrillated cellulose(MFC) were extracted by Alila et al.[23] from of several non-woody plants (basts of flax, hemp, jute, leaves of sisal and abaca) under high pressure homogenization process at a pressure lower than 600 bar. The pretreatment of alkaline pulping process and TEMPO-mediated oxidation were assistance for the fibrillation process. The fibrils width of jute 
with web-like structure was in the $30 \sim 50 \mathrm{~nm}$ range and several microns length. They also found that the fibers with the highest content of hemicelluloses help to get the highest yield in MFC.

Baheti et al.[24] extracted nanofiber from short fibers of jute spinning waste by high energy planetary ball milling process. The particle size was below $500 \mathrm{~nm}$ with narrow size distribution after 3 hours of wet milling in the deionized water. Wang et al.[25] prepared micro- and nano-fibrils from jute by chemical and high pressure steam treatments. micro-fibrils and nano-fibrils are observed and the diameter of the fibrils is about $0.1 \sim 3 \mu \mathrm{m}$. Abraham et al.[26] obtained an aqueous stable colloid suspension of cellulose nano fibrils from jute using steam explosion technique along with mild chemical treatment. The jute nanocellulose size is in the range of 15 25 nm in diameter. Lin et al.[27] extracted the cellulose nanofibrils from the jute fibers after the pre-treatments followed by the TEMPO mediated oxidation and mechanical disintegration. The diameter of cellulose nanofibrils was at a ranging from $5 \mathrm{~nm}$ to $20 \mathrm{~nm}$ and a length of several micrometers. Cellulose aerogels was formed by the lyophilization of nanofibrils dispersions with different concerntrations. The cellulose aerogels has many potential applications like pharmaceutical, liquid filtration and tissue engineering scaffolds.

\subsection{Nano cellulose whiskers}

Jute cellulose nanowhiskers (NCW) are a kind of renewable and biocompatible nanomaterials cause much interest because of its versatility in various applications. NCW exhibited elastic moduli as high as $100 \sim 150 \mathrm{GPa}$, and high aspect ratio (10-100), with diameters ranging from 4 to 20 $\mathrm{nm}[28]$.

The elementary unit of jute cellulose I structure is monoclinic. Cellulose is a carbohydrate of very high molecular wight and represented by the formula $\left(\mathrm{C}_{6} \mathrm{H}_{10} \mathrm{O}_{5}\right)$ n. These elementary units are repeated at regular spacing along the length of the fiber to form one long fiber molecule. One micelle is formed by such several molecular fibers in sideways arrangement as in a crystal. These micelles are arranged parallel to each other along the chain length in fibers[29]. The cellulose structure is divided into two regions, a crystalline region and an amorphous region, which is responsible for the transverse cleavage of the microfibrils into short monocrystals under acid hydrolysis[30]. Among the commercially available acids, the commonly used are hydrochloric, sulphuric, formic and phosphoric acid. The most frequently used is sulphuric acid. Due to the $\mathrm{H}_{2} \mathrm{SO}_{4}$ prepared whiskers present a negatively charged surface, which leads to more table whiskers aqueous suspension than that prepared using hydrochloric acid[31]. The oxidation of the whiskers or the post-sulfation of $\mathrm{HCl}$ is the other options to get charged whisker[32,33].

Kasyapi et al.[34] extracted bionanowhiskers from jute by acid hydrolysis combined with alkali pretreatment. After $1 \mathrm{~h}$ of acid hydrolysis, the rod like morphology was observed .And the nano whiskers with the length and width of $550 \pm 100 \mathrm{~nm}, 77 \pm 30 \mathrm{~nm}$ respectively. These nanowhiskers might be useful as reinforcing phase in nanocomposites. Jahan et al.[35] extracted cellulose from jute fibers at a yield of $59.8 \%$ based on the formic acid \& peroxy formic acid process at an atmospheric pressure. The microcrystalline cellulose were further to be obtained by sulphuric acid hydrolysis process. The diameter of nanofibers was $15 \sim 40 \mathrm{~nm}$. Cao et al. [4] extracted cellulose nanowhiskers from jute fibers by a 2,2,6,6-tetramethylpiperidine -1-oxyl radical (TEMPO)/ $\mathrm{NaBr} /$ $\mathrm{NaClO}$ system selective oxidization combined with mechanical homogenization with over $80 \%$ yield. The diameters of jute cellulose nanowhiskers was around 3 10 nm with high crystallinity (69.72\%). Cao et al.[36] also obtained spider-web-like nanoporous networks by simple directly immersion-drying method. The jute cellulose nanowhiskers $(3 \sim 10 \mathrm{~nm})$ deposited on the electrospun nanofibrous membrane (100 300nm), formed the spider-web-like nanoporous networks, which has potential useful for filter applications.

\section{Jute nanocomposites}

Nanocomposites in general are two-phase materials, and one of the phases has at least one dimension in the nanometer range $(1 \sim 100 \mathrm{~nm})$. The advantages of nanocomposite materials when compared with traditional composites are their superior thermal, mechanical, barrier properties, recyclability, transparency and low weight even at low volume fraction of nanofibers[37].

The first report of the use of cellulose nanofibers as a reinforcing phase in composite materials was by Favier et al.[38] in 1995. Since then a huge number of literature has been related to cellulose 
nano composite, and it is becoming an increasingly popular subject. Many methods about nano cellulose surface modification have been applied for improve the compatibility between nanofibers with matrices such as corona, plasma discharges, graft copolymerization or application of surfactant[39].

Kunal Das et al.[40,41] prepared nanofibers from jute by acid hydrolysis method. Starch/polyvinyl alcohol (PVA) \& Biocopolyester matrix based biocomposite reinforced with jute nanofibers at different loading (5, 10 and 15 wt. \%). The $10 \mathrm{wt}$. \% jute nanofibers loaded films exhibited best combination of properties. Baheti prepared nanofibers for reinforcement of polylactic acid (PLA) films by solvent casting. The nanofibers extracted from jute waste fibers with size around 50 500 nm after by high energy planetary ball milling in wet condition for 3 hours. After added of $5 \mathrm{wt}$. \% jute nanoparticles, it was observed that glass transition temperature (Tg) of PVA films improved from $84.36^{\circ} \mathrm{C}$ to $95.22^{\circ} \mathrm{C}$. Dynamic mechanical analysis of composite films showed higher value of $14 \times 108 \mathrm{~Pa}$ for storage modulus in comparison to $9 \times 108 \mathrm{~Pa}$ of neat composite film[42]. The Young's modulus was increased to 3.3GPa from 1.0GPa as compared with neat PLA film[43,44].The initial modulus and tensile strength increased by $217.30 \%$ and $170.59 \%$, respectively as compared to neat PLA film[45]. The mechanical properties of $3 \%$ loading of treated jute nanofibrils as reinforcement in PLA matrix are also found to be improved. Comparing with the pure PLA film, the initial modulus and tensile strength increased by $207.69 \%$ and $168.67 \%$ respectively[46]. The composite film has the potential applications such as food packaging, agriculture mulch films, automotive plastics, etc. Padal used jute nanofibers as reinforcement in epoxy resin matrix composites. The composites were prepared 50wt. \% of glass fiber and 50wt. \% epoxy resin content. Cellulose nanofibers are extracted from jute by a chemical and high energy ball milling. The nano particle size were distributed from micro to $20 \sim 50 \mathrm{~nm}$ with spherical and elliptical shape. The mechanical properties of nanocomposite has improve remarkably when 3 wt. \% Jute was added as reinforcement[47]. The tensile strength of nanocomposite was increased to $96 \%$ with the 3wt. \% nanofiber reinforcement as compared to the pure composite. This composite has the potential for high damping applications because the damping parameters of the nanofiber composites much higher than the pure composites[48]. Maiti et al.[49] prepared biocopolyester composite sheets with $2 \%$ and 10 wt. \% Jute nano fiber (JNF), and compostability tests were performed in simulated aerobic compost environment at ambient temperature for a period of 50 days. Weight loss study revealed that the incorporation of JNF enhanced the rate of degradation significantly. Molecular weight study revealed the fact that biocopolyester molecules had a significant breakdown in chain length during melt mixing with $10 \mathrm{wt}$. \% JNF. Rahman et al.[50] extracted crystalline cellulose from jute by hydrolysis with $40 \% \mathrm{H}_{2} \mathrm{SO}_{4}$ to get mixture of micro/nanocrystals. Biodegradable nanocomposites were prepared by extrusion and hot press method using jute crystalline cellulose (3-15\%) and poly (lactic acid).Vicker hardness and yield strength were found to increase with increasing cellulose content in the composite. The antibacterial effect were found after filling with $15 \%$ crystalline cellulose in the composite .The composite might be suitable for biomedical application because of the antibacterial effect and its cytotoxicity.

\section{Conclusions}

This article summarizes some of the recent advances in extraction of nanofibers from jute and their potential uses in nanocomposite. Jute fiber is a cheap, abundant, and renewable source with high cellulose content like 60 70\%. It's found to be excellent precursor for the extraction of cellulose nanoparticles. Owing to its outstanding performance, the nanofiber of jute has already become an important and hot spot in the nanomaterials study. Furthermore, application of jute nanofibers as reinforcement improves polymer mechanical properties such as tensile strength and modulus even at very low volume fraction. The nanocomposite could be used as packaging, electronic device, biomedical, cosmetic, tissue engineering scaffolds, filtration media, rheology modifiers, adsorbents, paper reinforcement and so on. As lignocellulosic fiber, there are some problems need to be solved in order to nanofiber commercial production: (1) The removal of noncelluosic materials of fibers with high efficiency is helpful for nanoparticle size reduction and nanofiber-matrix adhesion. (2) The nanofiber disintegration process should be optimized for the reduction of high energy consumption. (3) The requirements of chemical modification of nanofibers 
in order to improve compatibility with apolar matrix. The reactive hydroxyl groups on the surface of nano cellulose also provide the possibility for fabricating a wide range of functionalized materials for future advanced applications.

\section{Acknowledgments}

This research has been supported by "the Fundamental Research Funds for the Central Universities".

\section{Reference}

[1]. Atkinson R R. Jute fibre to yarn. Bombay: B.I. Publications,1965 年, p. 27-37.

[2]. Kundu B C. Jute-world's foremost bast fibre, II. Technology, marketing, production and utilization. Economic botany. Vol.10(1956)No.3,p.203-240.

[3]. Siró I, Plackett D. Microfibrillated cellulose and new nanocomposite materials: a review. Cellulose. Vol.17(2010)No.3,p.459-494.

[4]. Cao X, Ding B, Yu J, et al. Cellulose nanowhiskers extracted from TEMPO-oxidized jute fibers. Carbohydrate polymers.Vol.90(2012)No.2,p.1075-1080.

[5]. Ahmad E E M, Luyt A S. Morphology, thermal, and dynamic mechanical properties of poly (lactic acid)/sisal whisker nanocomposites. Polymer Composites. Vol.33(2012)No.6,p.1025-1032.

[6]. Johar N, Ahmad I, Dufresne A. Extraction, preparation and characterization of cellulose fibres and nanocrystals from rice husk. Industrial Crops and Products.Vol.37(2012)No.1,p.93-99.

[7]. Lin N, Dufresne A. Nanocellulose in biomedicine: current status and future prospect. European Polymer Journal. Vol.59(2014),p.302-325.

[8]. DENKBAŞ E B, Vaseashta A. Nanotechnology in medicine and health sciences. Nano. Vol.3(2008)No.4,p.263-269.

[9]. Franck R R. Bast and other plant fibres. Woodhead. Cambridge, 2005 年, p. 14.

[10]. John M J, Thomas S. Biofibres and biocomposites. Carbohydrate polymers. Vol.71(2008) No.3, p.343-364.

[11]. Morán J I, Alvarez V A, Cyras V P, et al. Extraction of cellulose and preparation of nanocellulose from sisal fibers. Cellulose. Vol.15(2008)No.1,p.149-159.

[12]. Klemm D, Heublein B, Fink H P, et al. Cellulose: fascinating biopolymer and sustainable raw material. Angewandte Chemie International Edition. Vol.44(2005)No.22,p.3358-3393.

[13]. Jarvis M. Chemistry: cellulose stacks up. Nature. Vol.426(2003)No.6967,p.611-612.

[14]. Mukherjee A C, Mukhopadhyay A K, Mukhopadhyay U. Surface characteristics of jute fibers at different stages of growth. Textile Research Journal. Vol.56(1986)No.9,p.562-566.

[15]. Liu L, Wang Q, Xia Z, et al. Mechanical modification of degummed jute fibre for high value textile end uses. Industrial Crops and Products. Vol.31(2010)No.1,p.43-47.

[16]. Mukherjee A, Ganguly P K, Sur D. Structural mechanics of jute: the effects of hemicellulose or lignin removal. Journal of the Textile Institute. Vol.84(1993)No.3,p.348-353.

[17]. Mukhopadhyay A K, Bandyopadhyay S K, Mukhopadhyay U. Jute fibers under scanning electron microscopy. Textile research journal. Vol.55(1985)No.12,p.733-737.

[18]. Azizi Samir M A S, Alloin F, Dufresne A. Review of recent research into cellulosic whiskers, their properties and their application in nanocomposite field. Biomacromolecules. Vol.6(2005)No.2,p.612-626.

[19]. Mohanty A K, Misra M. Studies on jute composites-A literature review. Polymer-Plastics 
Technology and Engineering. Vol.34(1995)No.5,p.729-792.

[20]. Heyn A N J. The microcrystalline structure of cellulose in cell walls of cotton, ramie, and jute fibers as revealed by negative staining of sections. The Journal of cell biology. Vol.29(1966)No.2,p.181-197.

[21]. Mukherjee S M, Sikorski J, Woods H J. Electron-microscopy of degraded cellulose fibres. Journal of the Textile Institute Transactions. Vol.43(1952)No.4,p.196-201.

[22]. Boufi S. Nanofibrillated Cellulose: Sustainable Nanofiller with Broad Potentials Use.Biomass and Bioenergy. Springer International Publishing,2014 年,p.267-305.

[23]. Alila S, Besbes I, Vilar M R, et al. Non-woody plants as raw materials for production of microfibrillated cellulose (MFC): a comparative study. Industrial Crops and Products. Vol.41(2013),p.250-259.

[24]. Baheti V, Abbasi R, Militky J. Ball milling of jute fibre wastes to prepare nanocellulose. World Journal of Engineering. Vol.9(2012)No.1,p.45-50.

[25]. Wang H, Huang L, Lu Y. Preparation and characterization of micro-and nano-fibrils from jute. Fibers and Polymers. Vol.10(2009)No.4,p.442-445.

[26]. Abraham E, Deepa B, Pothan L A, et al. Extraction of nanocellulose fibrils from lignocellulosic fibres: a novel approach. Carbohydrate Polymers.Vol.86(2011)No.4,p.1468-1475.

[27]. Lin J, Yu L, Tian F, et al. Cellulose nanofibrils aerogels generated from jute fibers. Carbohydrate polymers. Vol.109(2014),p.35-43.

[28]. Eichhorn S J. Cellulose nanowhiskers: promising materials for advanced applications. Soft Matter. Vol.7(2011)No.2,p.303-315.

[29]. Banerjee K, Roy A. THE STRUCTURE OF JUTE FIBRE BY X-RAY DIFFRACTION METHOD. Proc. Nat. Inst. Sci.Vol.7(1941),p.376.

[30]. Håkansson H, Ahlgren P. Acid hydrolysis of some industrial pulps: effect of hydrolysis conditions and raw material. Cellulose. Vol.12(2005)No.2,p.177-183.

[31]. Dong X M, Revol J F, Gray D G. Effect of microcrystallite preparation conditions on the formation of colloid crystals of cellulose. Cellulose. Vol.5(1998)No.1,p.19-32.

[32]. Araki J, Wada M, Kuga S. Steric stabilization of a cellulose microcrystal suspension by poly (ethylene glycol) grafting. Langmuir. Vol.17(2001)No.1,p.21-27.

[33]. Araki J, Wada M, Kuga S, et al. J wood Sc. Vol.45(1999),p.258.

[34]. Kasyapi N, Chaudhary V, Bhowmick A K. Bionanowhiskers from jute: Preparation and characterization. Carbohydrate polymers. Vol.92(2013)No.2,p.1116-1123.

[35]. Jahan $\mathrm{M} \mathrm{S}$, Saeed $\mathrm{A}, \mathrm{He} \mathrm{Z}$, et al. Jute as raw material for the preparation of microcrystalline cellulose. Cellulose. Vol.18(2011)No.2,p.451-459.

[36]. Cao X, Wang X, Ding B, et al. Novel spider-web-like nanoporous networks based on jute cellulose nanowhiskers. Carbohydrate polymers. Vol.92(2013)No.2,p.2041-2047.

[37]. Eichhorn S J, Dufresne A, Aranguren M, et al. Review: current international research into cellulose nanofibres and nanocomposites. Journal of Materials Science.Vol.45(2010)No.1,p.1-33.

[38]. Favier V, Canova G R, Cavaillé J Y, et al. Nanocomposite materials from latex and cellulose whiskers. Polymers for Advanced Technologies. Vol.6(1995)No.5,p.351-355.

[39]. Missoum K, Belgacem M N, Bras J. Nanofibrillated cellulose surface modification: a review. Materials. Vol.6(2013)No.5,p.1745-1766.

[40]. Das K, Ray D, Bandyopadhyay N R, et al. Physico-mechanical properties of the jute micro/nanofibril reinforced starch/polyvinyl alcohol biocomposite films. Composites Part B: Engineering. Vol.42(2011)No.3,p.376-381. 
[41]. Das K, Ray D, Banerjee C, et al. Physicomechanical and thermal properties of jute-nanofiber-reinforced biocopolyester composites. Industrial \& Engineering Chemistry Research. Vol.49(2010)No.6,p.2775-2782.

[42]. Baheti V, Militky J. Reinforcement of wet milled jute nano/micro particles in polyvinyl alcohol films. Fibers and Polymers. Vol.14(2013)No.1,p.133-137.

[43]. Baheti V, Militky J, Ul Hassan S Z. Polylactic Acid (PLA) Composite Films Reinforced with Wet Milled Jute Nanofibers. Conference Papers in Science. Hindawi Publishing Corporation, 2013 年,p.1-6.

[44]. Baheti V, Militky J, Mishra R, et al. Wet Pulverization of Waste Jute Fibers as Reinforcement for Biodegradable Nanocomposite Films. Journal of Textile Science \& Engineering. Vol.3(2013),p.130.

[45]. Baheti V, Militky J, Marsalkova M. Mechanical properties of poly lactic acid composite films reinforced with wet milled jute nanofibers. Polymer Composites. Vol.34(2013)No.12,p.2133-2141.

[46]. Baheti V, Mishra R, Militky J, et al. Influence of noncellulosic contents on nano scale refinement of waste jute fibers for reinforcement in polylactic acid films. Fibers and Polymers. Vol.15(2014)No.7,p.1500-1506.

[47]. Padal K T B, Ramji K, Prasad V V S. Mechanical Properties of Jute Nanofibres Reinforced Composites. Global Journal of Researches in Engineering. Vol.14 (2014)No.4.

[48]. Padal K T B, Ramji K, Prasad V V S. Damping Behavior of Jute Nano Fibre Reinforced Composites. International Journal of Emerging Technology and Advanced Engineering. Vol.4(2014)No.4,p.753-759.

[49]. Maiti S, Ray D, Mitra D, et al. Study of compostable behavior of jute nano fiber reinforced biocopolyester composites in aerobic compost environment. Journal of Applied Polymer Science. Vol.123(2012)No.5,p.2952-2958.

[50]. Rahman M M, Afrin S, Haque P, et al. Preparation and characterization of jute cellulose crystals-reinforced poly (l-lactic acid) biocomposite for biomedical applications. International Journal of Chemical Engineering. Vol.2014(2014). 